\title{
LA REINVENCIÓN DEL RÍO DESDE LO RECREATIVO
}

La transformación de la ribera Metropolitana de Rosario (Argentina) desde una mirada sobre el espacio público y las huellas patrimonialés

Cecilia Inés Galimberti

Arquitecta, doctoranda de la Facultad de Arquitectura, Planeamiento y Diseño dela Universidad Nacional de Rosario, Argentina (FAPyD, UNR). Becaria PG TII del CONICET. Integrante del Centro Universitario Rosario de Investigaciones Urbanas y Regionales (CURDIUR). Docente del Área de Teoría y Técnica Urbanística y de Historià de la Arquitectura de la FAPyD - UNR.

CURDIUR, FAPyD, UNR - CONICET. 


\title{
Cecilia Inés Galimberti
}

\begin{abstract}
Resumen
En el marco de las reconversiones de waterfronts contemporáneas, el presente artículo se propone analizar las transformaciones ribereñas, desde la perspectiva recreativa, que suceden en las últimas tres décadas en la ribera metropolitana de Rosario, Argentina. La ciudad de Rosario resulta un caso emblemático a nivel nacional de continuidad de políticas públicas en la transformación de su frente costero. No obstante, en los últimos años, este proceso también comienza a desarrollarse en otras localidades de su Región Metropolitana. En este sentido, este trabajo plantea reflexionar sobre estas transformaciones desde una mirada integrada a toda la región, a fin de interpretar si resultan articuladas y desde un accionar atento al ambiente ribereño.
\end{abstract}

\section{Palabras clave}

Transformaciones ribereñas, nuevos usos recreativos, región metropolitana, reapropiación del espacio público, atracción turística.

THE REDISCOVERY OF RIVERINE COASTS FROM A RECREATIONAL PERSPECTIVE. THE TRASFORMATION OF THE METROPOLITAN COAST OF ROSARIO (ARGENTINA) FROM THE OUTLOOK OF PUBLIC SPACE AND PATRIMONIAL MARKERS

\begin{abstract}
Within the framework of the contemporary restructuring of waterfronts, this article intends to analyze riparian transformations, from a recreational perspective, that took place during the last three decades in the Metropolitan River Coast of Rosario, Argentina. The city of Rosario, is a nationwide emblematic case of continuity of public policy in the transformation of its waterfront. However, in recent years, this process has also begun to develop in other waterfront locations within the Metropolitan Region. In this sense, this work reflects on these changes from a metropolitan perspective, in order to interpret whether they are articulated with one another and consider their effects in relation to the coastal environment.
\end{abstract}

Keywords

Riverside transformations, new recreational uses, metropolitan region, reappropriation of public space, tourist attraction. 


\section{LA REINVENCIÓN DEL RÍO DESDE LO RECREATIVO}

La transformación de la ribera Metropolitana de Rosario (Argentina) desde una mirada sobre el espacio público y las huellas patrimoniales

\section{INTRODUCCIÓN}

Gran parte de las ciudades costeras a nivel mundial, en las últimas décadas, afrontan transformaciones territoriales en sus waterfronts. El capitalismo y los cambios en los modos de producción modifican las lógicas de las instalaciones portuarias, productivas e industriales, a partir de nuevas solicitudes y necesidades. Asimismo, las transformaciones urbanas - expansión, recualificación, metropolización, entre otras - requieren recuperar estos espacios para la población, re-articulando los extensos frentes costeros a la trama urbana, generalmente disociados históricamente.

En este sentido, el presente artículo propone analizar las transformaciones ribereñas vinculadas con lo recreativo, acontecidas en los últimos treinta años en la ribera metropolitana de Rosario, Argentina. Este proceso de reconversión, en primer lugar, se inicia en la ciudad de Rosario; pero, con el transcurrir de los años, también se verifica en diversas localidades ribereñas pertenecientes a la región metropolitana.

En Rosario, la consigna de recuperación del frente ribereño del río Paraná para disfrute de la población resulta un proyecto recurrente desde las primeras décadas del siglo XX, presente en el imaginario colectivo, como también en los diversos planes reguladores locales. ${ }^{1}$ No obstante, no es hasta la recuperación democrática de 1983 cuando estos lineamientos logran materializarse, a través del accionar conjunto y articulado de un gran número de actores, que ya prefigurando el cambio desde el proyecto y la teoría, encuentran en los nuevos lineamientos municipales el ámbito ideal para concretar viejos anhelos de recuperar la ribera central de la ciudad, desde una nueva mirada sobre el espacio público y las huellas patrimoniales existentes.

A su vez, se lleva a cabo una serie de proyectos articulados que buscan una recuperación ribereña continua desde el norte hasta el sur de la ciudad, desde el punto de vista recreativo, vial, turístico, cultural, residencial y comercial. La condición productiva de la ribera, cuyas instalaciones ferroviarias y portuarias, a comienzos de la década del 80, ocupan 11 $\mathrm{km}$ de extensión de los $16,7 \mathrm{~km}$ que posee la totalidad del frente costero occidental, resulta condicionante en cuanto a las intervenciones necesarias para reinventar la relación anhelada entre la ciudad y el río.
1-Especialmente a partir del Plan Regulador y de Extensión de 1935, realizado por el ingeniero y urbanista CARLOS M. DELLAPAOLERA, el arquitecto e ingeniero ANGEL GUIDO y el ingeniero ADOLFO P. FARENGO. 


\section{Cecilia Inés Galimberti}

La ribera rosarina, a partir de un accionar continuo en el tiempo, se constituye como un nuevo frente urbano. Es de remarcar que simultáneamente con esta iniciativa se produce un cambio en la relación con el río y sus islas, visto como enclave ideal para disfrute, recreación y espacio para actividades náuticas-deportivas. Se incrementa vertiginosamente,

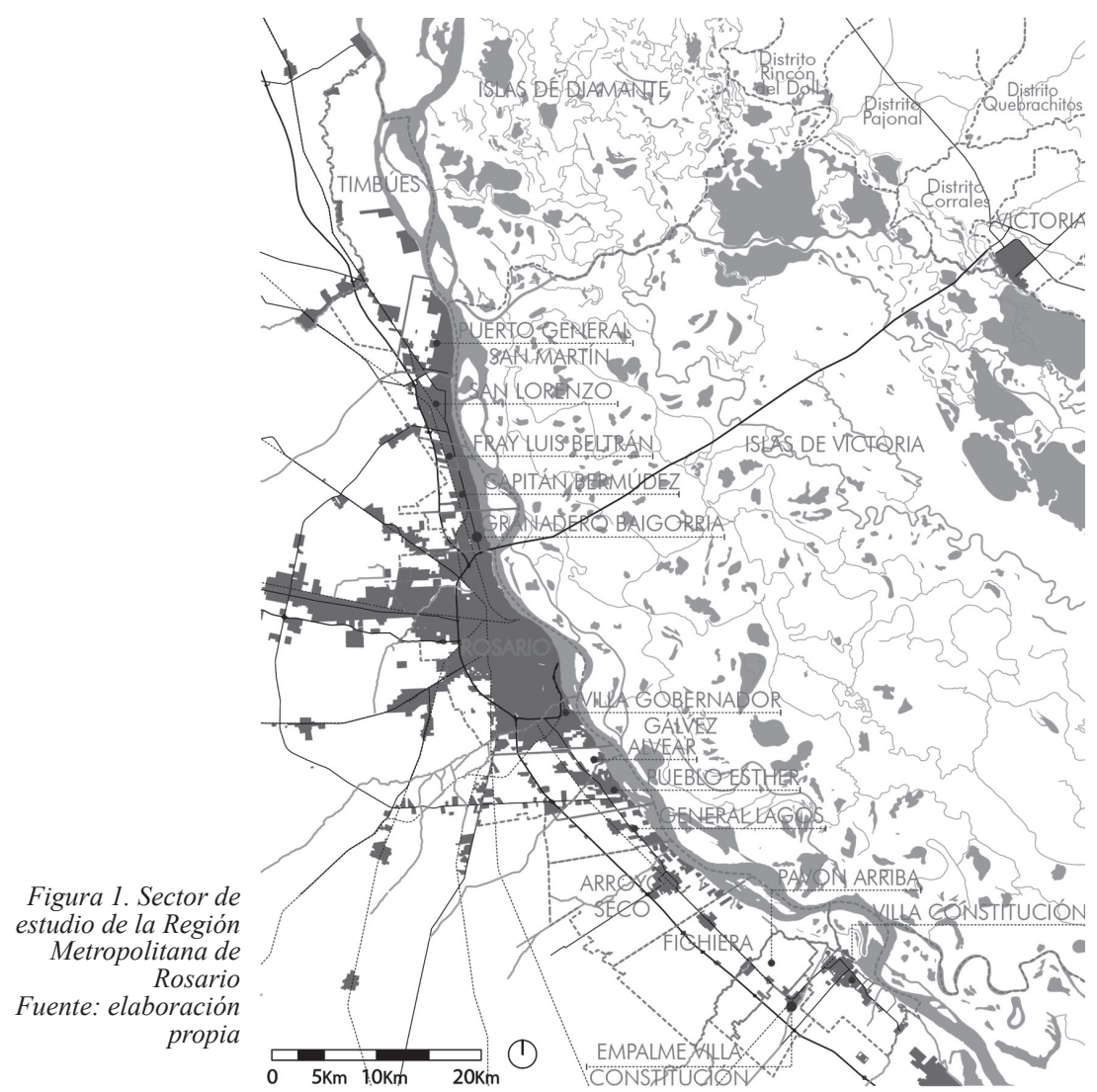

en las últimas décadas, la población que adopta estas actividades, y crecen en gran medida la plaza náutica y los emprendimientos turísticos y recreativos en los clubes costeros y las islas.

Asimismo, la inauguración del puente Rosario-Victoria posibilita un nuevo entramado de factores y oportunidades. La ciudad de Victoria se incorpora a esta región metropolitana, especialmente como referente turístico y recreativo, concentrando en esta última década diversas actividades y servicios vinculados con esta oferta. Se establece así una dialéctica cada vez más fluida entre ambas riberas del Paraná.

Esta recuperación de la ribera, el río y las islas, como espacios recreativos, también se produce en otras localidades de la Región Metropolitana de Rosario, en los últimos treinta años. Especialmente, a partir de una re- 


\section{LA REINVENCIÓN DEL RÍO DESDE LO RECREATIVO \\ La transformación de la ribera Metropolitana de Rosario (Argentina) desde una mirada sobre el espacio público y las huellas patrimoniales}

lectura de composición de espacios públicos y una reinvención del río como práctica colectiva, el conjunto de la ribera del Paraná con sus islas se convierte en foco turístico regional y nacional. De manera que, durante el período de estudio, se produce una reinvención del río desde lo recreativo. Se posibilitan así nuevas configuraciones territoriales atentas a los componentes ambientales existentes, que resultaban desconocidas o inaccesibles para gran parte de la población regional.

\section{Reclamo Popular de recuperar el río}

El reclamo de dejar de dar la espalda al río es reiterado por gran parte de los rosarinos, especialmente entre las décadas de 1970 y 1980. Se solicita así poder volver hacia el río, es decir, reinventarlo. Esta consigna de recuperar el río para la población no solo se evidencia en cartografías oficiales, sino que se refleja también en el imaginario colectivo, en el cual se presenta la necesidad de los ciudadanos de relacionarse con la ribera del Paraná de un modo distinto.

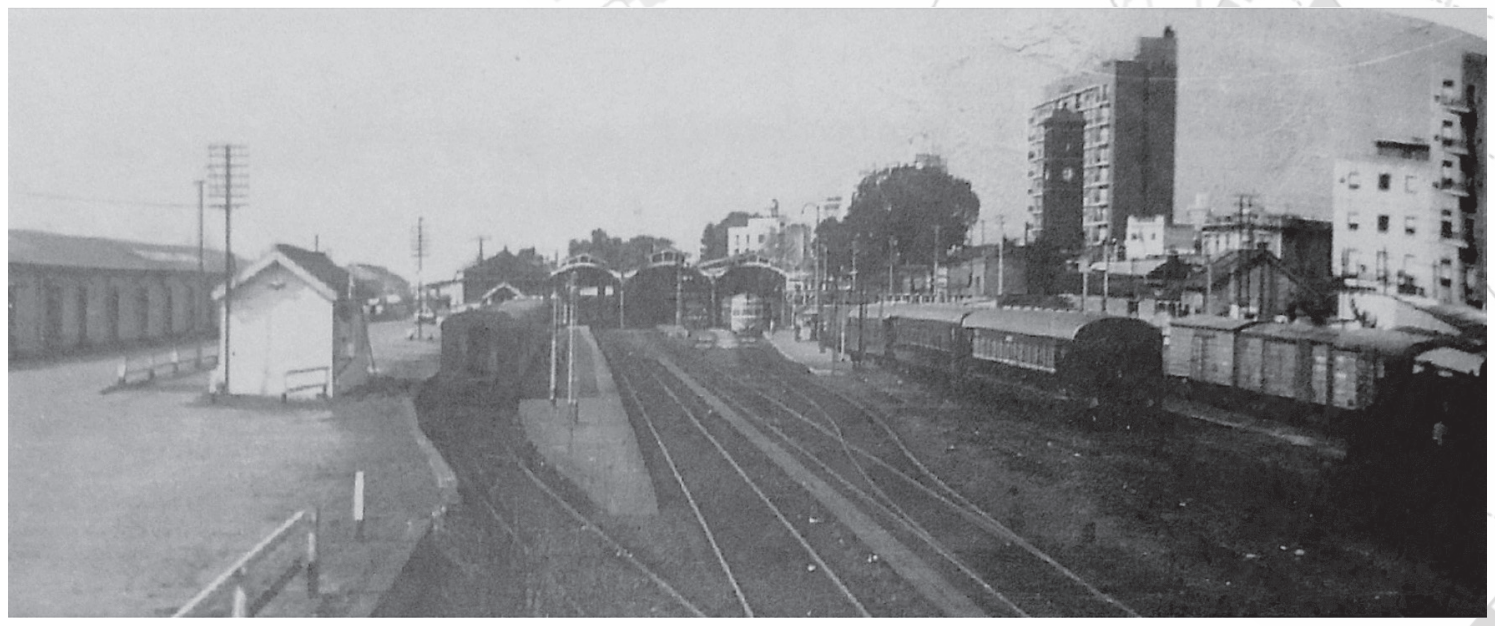

Figura 2. Foto de la Estación Rosario Central en 1967. Diez años después fue clausurada y abandonada Fuente: FERRER Y FERNANDEZ PRIOTTI, 2001 


\section{Cecilia Inés Galimberti}

2- Nota "Sacarle el jugo al Paraná" - Revista Risario $N .^{\circ} 32$ - primera quincena de febrero de 1986.

3- Nota "La ciudad gana espacios y descubre rincones ocultos del majestuoso Paraná", Diario La Capital, sábado 6 de junio de 1998.
Las infraestructuras ferro-portuarias ubicadas a lo largo de la costa de Rosario resultan también un obstáculo para este imaginario. Principalmente después de su desafectación, cuando el abandono y el vacío expectante hace eco en muchas manifestaciones artísticas, como sucede por ejemplo en la literatura: "Rosario Norte es el esqueleto de lo que fue. Una estación despojada de trenes, de gente y de movimiento. Y carcomida por la inacción de los años en desuso. La entrada principal está cerrada por un tejido y más allá pueden verse montículos de arena y bolsas de cemento. [...] Entro por una puerta lateral, que da sobre la antigua playa de estacionamiento, y me deslizo debajo de la bóveda que cubre las vías principales. Solo veo a un par de obreros descargando material sobre el viejo andén. [...] Un poco más allá de la bóveda están los galpones donde comienza el Crotario. Casillas, depósitos o viviendas que antes estaban ocupadas por el ferrocarril" (Briguet, 1988).

Dichas instalaciones comenzaron a percibirse como una barrera entre la ciudad y el río; situación que se acentuaba con la existencia de los largos paredones de las infraestructuras ferroviarias que parecían dividir la ciudad en dos. De este modo, entre las décadas de los 70 y los 90, la frase darle la espalda al río resonaba continuamente en el imaginario de la época, el cual se reflejaba, por ejemplo, en los diarios y revistas de esos años: "[...] me sentí avergonzado más de una vez por la indiferencia hacia ese inmenso río que pasa por nuestras narices y que nunca encontramos la forma realmente de sacarle el jugo. [...] Hoy pareciera que el Paraná se ha dado cuenta de todos los desprecios que se le han hecho y lentamente se está muriendo, o tal vez se va para otro país. Lo cierto es que cada día trae menos agua"2 (Revista Risario N. ${ }^{\circ} 32,1986$ ).

"Durante años la ciudad vivió a espaldas del río. Creció bajo la pujanza de las actividades portuarias pero se negó el privilegio de disfrutar lo que la naturaleza le brindó a manos llenas. Sin renegar de su destino inicial hoy se comprende que también es posible vivir junto al Paraná". ${ }^{3}$ (Diario La Capital, 6 de julio de 1998).

Desde los primeros estudios y propuestas realizadas durante el período de 1985 a 1991, que culmina con la presentación al Honorable Concejo Municipal del documento de Actualización del Plan Regulador de 1967 — comúnmente llamado Plan Director 1991—, se propone como operación estructural la "Recuperación del frente costero". Se plantea compatibilizar el rol productivo-portuario con el desarrollo recreativo y de turismo, y 


\section{LA REINVENCIÓN DEL RIIO DESDE LO RECREATIVO}

La transformación de la ribera Metropolitana de Rosario (Argentina) desde una mirada sobre el espacio público y las huellas patrimoniales

se distinguen tres tramos claramente diferenciados - según sus características y potencialidades - como unidades de planificación diferentes, que resultan ser: Costa Norte, Costa Central y Costa Sur. Esta operación estructural resulta clara, y se mantiene hasta la actualidad en materia de planeamiento. Es así que, en estas últimas tres décadas, se profundizan y desarrollan las diversas opciones de encuentro con el río, desde la náutica hasta la pesca deportiva, desde la contemplación al disfrute activo.

Gran parte de la población se vuelca al río para el disfrute de actividades recreativas. En este sentido, los clubes ribereños incrementan notablemente su número de socios, y sobre todo su plaza náutica. En este nuevo diálogo con el río, aquellas islas lejanas de propiedad ajena comienzan a participar activamente en la vida cotidiana de la población mediterránea. Se plantea una nueva

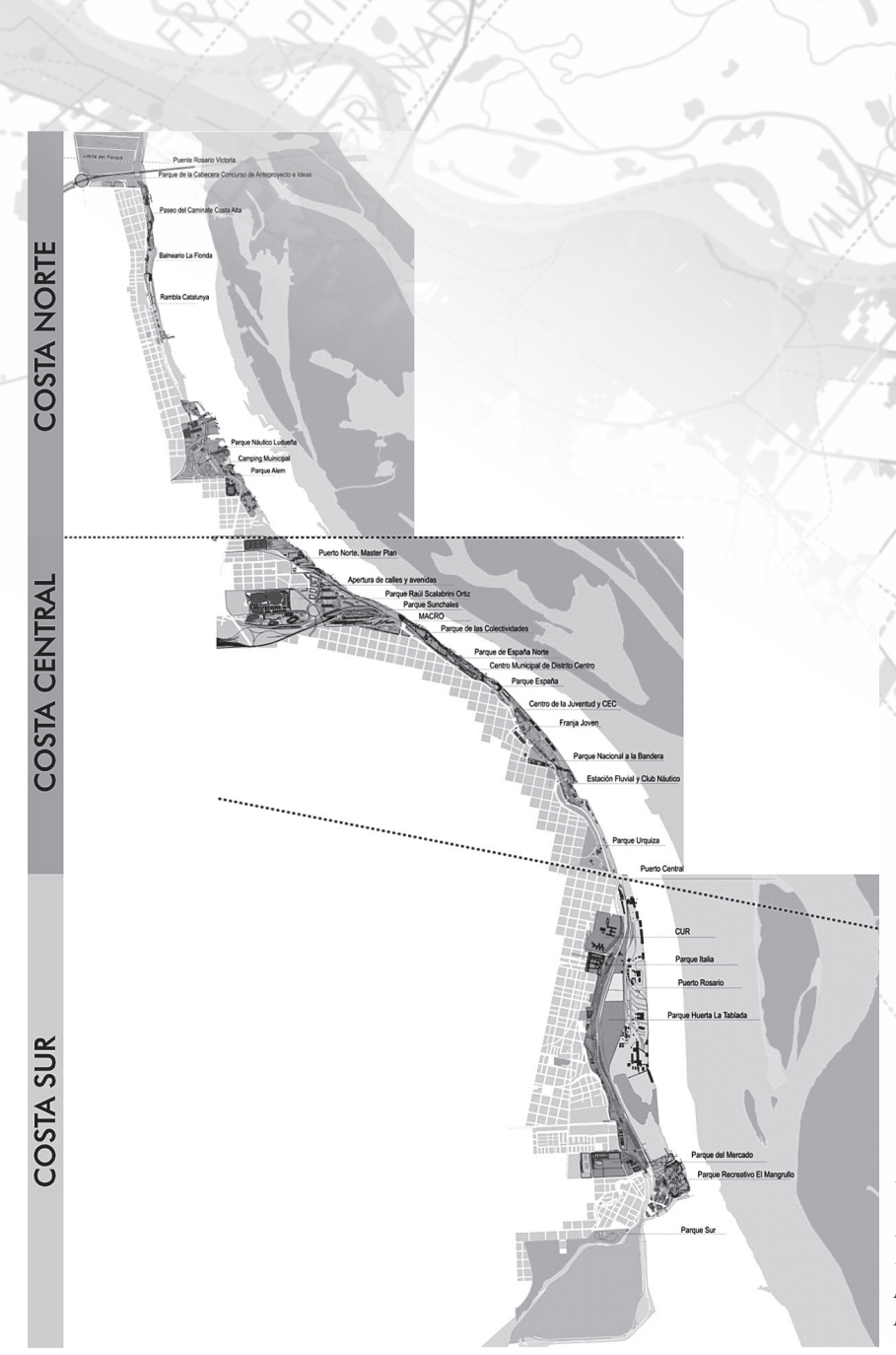

Figura 3. Sectorización norte, centro y sur. Plan Maestro de la Costa Fuente: elaboración propia sobre la base de planos del Plan Maestro de la Costa 


\section{Cecilia Inés Galimberti}

mirada sobre la vida del río, las islas y los isleños. Se reconoce desde el imaginario colectivo esa desvinculación, y se plantea la necesidad de recuperarla: "la falta de integración es casi total. Con la sola excepción de algunos deportistas que gustan incursionar por los canales interiores de las islas próximas, aquellas permanecen casi desconocidas para la casi totalidad de los numerosos rosarinos, que apenas vislumbran el fascinante mundo del río, su gente, su flora y su fauna, a través de los escasos miradores urbanos que existen entre nosotros" (Diario La Capital, 8 de noviembre de 1985).

Se incorporan así las prácticas recreativas y de goce del río, el aire y el sol. Los emprendimientos isleños en estos últimos años se multiplican, y se incrementan los balnearios de clubes y municipios en las islas. También se incrementa sostenidamente, año tras año, la flota náutica: kayaks, canoas, motos acuáticas, botes, veleros, lanchas, yates y cruceros. El crecimiento, en estas últimas décadas, es tan elevado, que actualmente se encuentra saturado el servicio de guarderías de la ciudad. Según datos de Prefectura, actualmente hay 10.200 embarcaciones registradas en Rosario, y según registros recientes se inscriben cuatrocientas nuevas embarcaciones por año. Si sumamos a este registro los kayaks y piraguas, se estima que el parque náutico total excede las 25.000 embarcaciones. A pesar de que existen más de veinticuatro espacios de guardado entre clubes y guarderías, se encuentran totalmente saturados. La mayoría de estos presentan amplias listas de espera -algunas que exceden la espera de más de setenta vehículos-.

Asimismo, es notable el crecimiento de estas guarderías y clubes ribereños con amarras y guardado en varias localidades ribereñas de la región, especialmente en los últimos años. Granadero Baigorria, Capitán Bermúdez, San Lorenzo y Pueblo Esther resultan las principales localidades elegidas para incrementar estos espacios, además del aumento de varios emprendimientos residenciales cerrados con amarras exclusivas. Según datos de la Cámara Náutica de Rosario, este frente ribereño resulta el segundo parque náutico más grande del país, luego del histórico delta de Buenos Aires.

De este modo, cambia totalmente la configuración de estas actividades, y su incremento excesivo trae consigo aspectos negativos, vinculados con estas prácticas. Por un lado, parte del imaginario considera desmedido este crecimiento, y advierte: "de esa ciudad que vivía 'de espaldas al río' ya no quedan rastros en la actualidad. Todo lo contrario. Hoy el gran riesgo que se corre es terminar viviendo de espaldas al resto de la ciudad, 


\section{LA REINVENCIŌN DEL RĨO DESDE LO RECREATIVO \\ La transformación de la ribera Metropolitana de Rosario (Argentina) desde una mirada sobre el espacio público y las huellas patrimoniales}
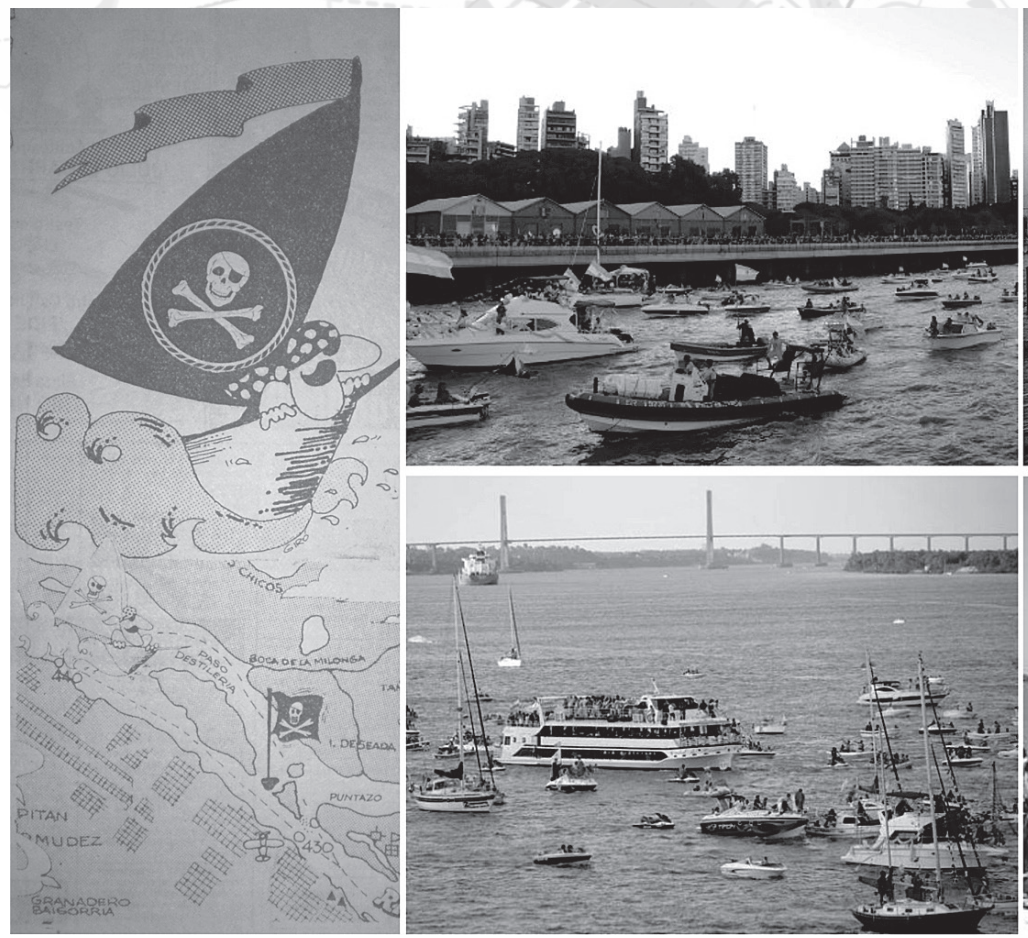
hacia el interior". 4 (Diario La Capital, 24 de enero de 2012).

También así, aumentan en los últimos años los accidentes náuticos debido a la compleja coexistencia de tantas actividades náuticas. Frente al incremento desmedido, por un lado, se contrapone una normativa obsoleta, vacíos existentes en la legislación vigente, como también ignorancia o desconocimiento de las reglas náuticas y cambios en las lógicas

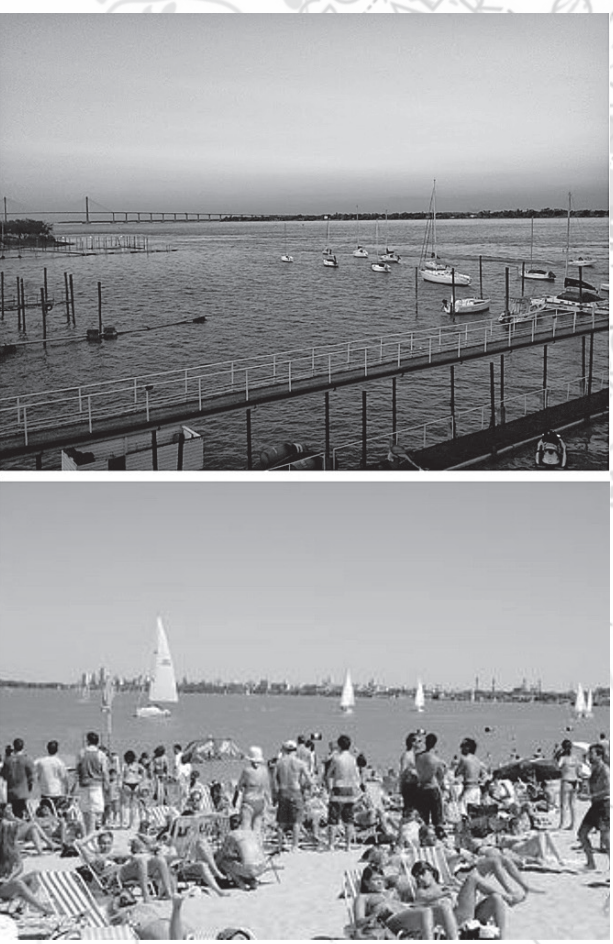

Figura 4. Izquierda: publicidad de Puerto Pirata 1988. Derecha: incremento sostenido de la flota náutica en el río Paraná vinculado. con el disfrute de este

Fuente: archivo diario La Capital y fotografias de la autora 


\section{Cecilia Inés Galimberti}

4- Nota periodística "De Espaldas al río o a la ciudad" de ADRIÁN GERBER, publicada en La Capital, 24 de enero de 2012.

5 En nota periodística "Un parque náutico de más de 8 mil kayaks y piraguas", publicada en La Capital, 13 de enero de 2013. debido a la masividad reciente. Es así que existe una división en el imaginario colectivo de aquellos que abrazaron al río y sus costumbres desde varias décadas atrás, y entre aquellos que se acercan en los últimos años. Por ejemplo, un remador histórico de estas aguas plantea: "la fisonomía del río y la isla cambiaron muchísimo. En aquel tiempo no era muy común venir al río, era como un destino extraño, y tampoco estaba el puente. El río estaba más asociado al concepto del isleño, del pescador, era como irse al extranjero. Te ibas a la isla y te decían que para qué, si allí no había nada. Justamente, de eso se trata. Era ir a encontrarte con todo lo que no hay en esta costa, en la ciudad. [...] Y no hace mucho tiempo que cambió la imagen del río, de lo que es su gente y sus usos y costumbres. En el río siempre se manejaron determinados niveles de cortesía y buenas costumbres, que lamentablemente se fueron perdiendo [...] Si hubiese mayor conciencia, respeto, aprendizaje y capacitación, sería buenísimo. Hoy por hoy, te das cuenta quién es un hombre de río y quién lo utiliza como moda, quién está de paso". ${ }^{5}$ (Diario La Capital, 13 de enero de 2013).

A su vez, la perspectiva regional del territorio que incorpora a la ciudad de Victoria y sus islas se encontraba vedada a gran parte de la población hasta la inauguración de la conexión vial en 2003. No obstante, para aquellos vinculados históricamente con la vida del río y sus prácticas náuticas, esta mirada resulta crucial: el río y sus islas como centro y enmarcado entre sus dos orillas.

\section{LA RECUPERACIÓN RIBEREÑA COMO ESPACIO RECREATIVO}

La reinvención del río como espacio recreativo constituye una de las transformaciones más significativas realizadas en estos últimos treinta años. Se establecen nuevos vínculos y relaciones con el río desde el aspecto recreativo, turístico y de esparcimiento. Por un lado, la ciudad de Rosario logra recuperar como espacio público gran parte de su frente costero central, y articular a través de lineamientos estratégicos una continuidad de todo su frente costero urbano, restableciendo el diálogo entre el río y la trama urbana. Este posicionamiento es tomado posteriormente por otras localidades ribereñas de la región, que plantean recuperar su ribera como espacio público.

Asimismo, como ya mencionamos, la inauguración del puente Rosario-Victoria posibilita una nueva reconfiguración regional, permitiendo "hacer visible" o "materializar" la 


\section{LA REINVENCIÓN DEL RÍO DESDE LO RECREATIVO}

La transformación de la ribera Metropolitana de Rosario (Argentina) desde una mirada sobre el espacio público y las huellas patrimoniales

otra orilla. Aquella ribera lejana, distante, se posiciona desde un nodo estratégico clave vinculado con el paisaje, la recreación y el disfrute del río. De este modo, en los últimos treinta años, se desatan diversos procesos de transformación en la ribera metropolitana, que reconfiguran un nuevo marco de posibilidades y potencialidades.

\section{Reconversión ribereña de la ciudad de Rosario}

Rosario, en las últimas tres décadas, logra configurar casi en su totalidad un recorrido ribereño público-recreativo, que transforma completamente el espacio público de la ciudad y mantiene las directrices previstas desde mediados de la década de 1980 hasta la actualidad. Se retoman las históricas expectativas sobre la recuperación de la costa, y se logra logrando así concretar el deseo de gran parte de la población de recobrar ese espacio, durante muchas décadas negado a la población. Según plantea el documento del Plan Director de 1991, la recuperación del frente costero "promueve el aprovechamiento integral de la costa, reivindicando y reafirmando el carácter litoral de la ciudad, compatibilizando su rol productivo-portuario con el desarrollo recreativo y de turismo microregional de la ribera y de los sectores desafectados de la actividad portuaria". 6

Se logra configurar así un corredor cultural, recreativo y turístico desde la actual cabecera del puente Rosario-Victoria hasta la desembocadura del arroyo Saladillo. La reconversión de este espacio público costero rosarino es ejemplo de la permanencia de los grandes proyectos urbano-territoriales en el tiempo y de la voluntad de llevarlos a cabo a partir de la continuidad en la gestión y en las directrices de planeamiento, aun a pesar de los diferentes partidos políticos presentes en el Ejecutivo en las últimas décadas.

Es así que el proceso de reconversión ribereña, si bien resulta un único proyecto estructural, se desarrolla en tres sectores o unidades de actuación delimitadas según sus características particulares, condiciones topográficas y paisajísticas, y sus potencialidades de uso. Se concentran así las diversas acciones y transformaciones en tres extensos tramos: Costa Norte, Costa Central y Costa Alta Sur.

1. La Costa Norte. Único enclave de utilización del río con fines recreativos y deportivos de la ciudad desde las primeras décadas del siglo XX, profundiza su vocación a partir de las intervenciones realizadas desde la década del 80, resultando clave, en este proceso de transformación, la construcción del Paseo Ribereño y la expansión de los balnearios
6- Tomo II "Actualización del Plan Regulador y Bases Documentales para la revisión del Código Urbano", Pág. 17. 


\section{Cecilia Inés Galimberti}

existentes. El sector delimitado por la Costa Norte, ubicado al norte de la ciudad, aborda desde el proyectado Parque de la Cabecera - límite jurisdiccional con Granadero Baigorria - hasta la planta potabilizadora de agua.

Las principales lineamientos que se abordan desde el retorno democrático consisten en consolidar como corredor recreativo la costanera norte a través del incremento del equipamiento recreativo - y la optimización del existente-, la recuperación de áreas para uso público y el reordenamiento de usos, aperturas y conexiones viales, la habilitación y extensión de nuevos sectores balnearios, puertos deportivos, camping y sectores de paseo, a fin de lograr un aprovechamiento integral recreativo-deportivo de la zona ribereña norte de Rosario.

2. Costa Central. La transformación de la ribera central de la ciudad de Rosario constituye una de las innovaciones más significativas de todo el frente costero urbano de la región. Este sector abarca la mayor parte de las instalaciones portuarias originales de Rosario, como también gran parte de infraestructura ferroviaria. La liberación de uso productivo de estas tierras y su conversión en espacio público constituye uno de los anhelos

Figura 5. Balneario La Florida

Fuente: Archivo Secretaría de Planeamiento MR más fuertes presentes en el imaginario colectivo, y uno de los proyectos recurrentes de mayor jerarquía en la historia de la planificación local. Con el puntapié inicial del Parque España, este corredor ribereño comienza su transformación y cambia su vocación a

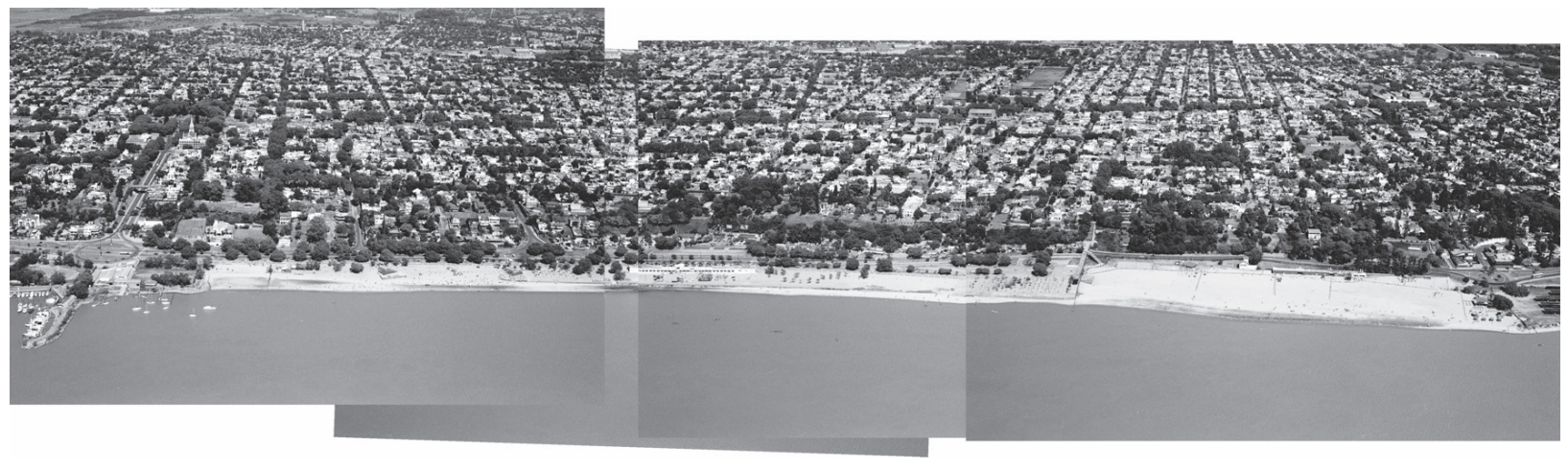




\section{LA REINVENCIÓN DEL RÍO DESDE LO RECREATIVO}

La transformación de la ribera Metropolitana de Rosario (Argentina) desde una mirada sobre el espacio público y las huellas patrimoniales

espacios públicos-recreativos. Es así que, en los últimos treinta años, se propone desde diversos frentes recuperar el "gran balcón al río".

Este sector ribereño del área central de la ciudad se convierte así en un parque polifuncional y un polo de atracción, que conforma un continuo de espacios públicos entre el Parque Sunchales, el Parque de las Colectividades, el Parque España, el Parque Nacional a la Bandera, la Estación Fluvial, los clubes náuticos y la futura incorporación de la Zona Franca de Bolivia. Este tramo, que comprende desde el Centro de Renovación Urbana Scalabrini Ortiz hasta la prolongación de la avenida Pellegrini, "asume el rol predominante de costa recreativa pública y cívica, debido a que son tierras e instalaciones del dominio municipal o provincial (este último comprende el área portuaria asignada por el ENAPRO a desarrollo urbano), destinadas a actividades de esparcimiento y turísticas, casi en su totalidad, e intimamente relacionadas con la centralidad tradicional de la ciudad”, como plantea el Plan Maestro de la Costa en 2007.

3. Costa Sur. El sector ribereño sur de la ciudad siempre ha mantenido un rol vinculado con lo productivo, presentando a su vez grandes condiciones de deterioro y abandono. La costa sur resulta el fragmento ribereño de Rosario que presenta mayores conflictos desde el punto de vista paisajístico, ambiental y de baja calidad de vida de gran parte de sus habitantes. Este sector encuentra, de este modo, la mayor deuda de la transformación urbanística ribereña. A pesar de resultar el fragmento ribereño con menor vocación recreativa, en estas últimas tres décadas se plantean diversos proyectos para reconvertir este sector desde el punto de vista recreativo - por ejemplo, la construcción del Complejo Recreativo Brazo Norte del Arroyo Saladillo_- Sin embargo, muchos de los proyectos recurrentes aún siguen siendo una cuenta pendiente, como resultan la preservación ambiental de la barranca sur; el completamiento y articulación entre el sistema de espacios verdes denominados " "de interfase puerto-ciudad", como el Parque Italia, el Parque La Tablada, el Parque del Mercado, los parques-huerta y el Parque Regional Sur; el reordenamiento del brazo norte del arroyo Saladillo, los clubes de pesca, el asentamiento El Mangrullo y la reestructuración del sector de la isla del Saladillo y del proyecto recreativo-comercial del Frigorífico Swift. ${ }^{8}$
7- Según el Plan Maestro de la Costa.

8- En coordinación con el Municipio de Villa Gobernador Gálvez. Ver propuesta de transformación en el capitulo 7 . 


\section{Cecilia Inés Galimberti}
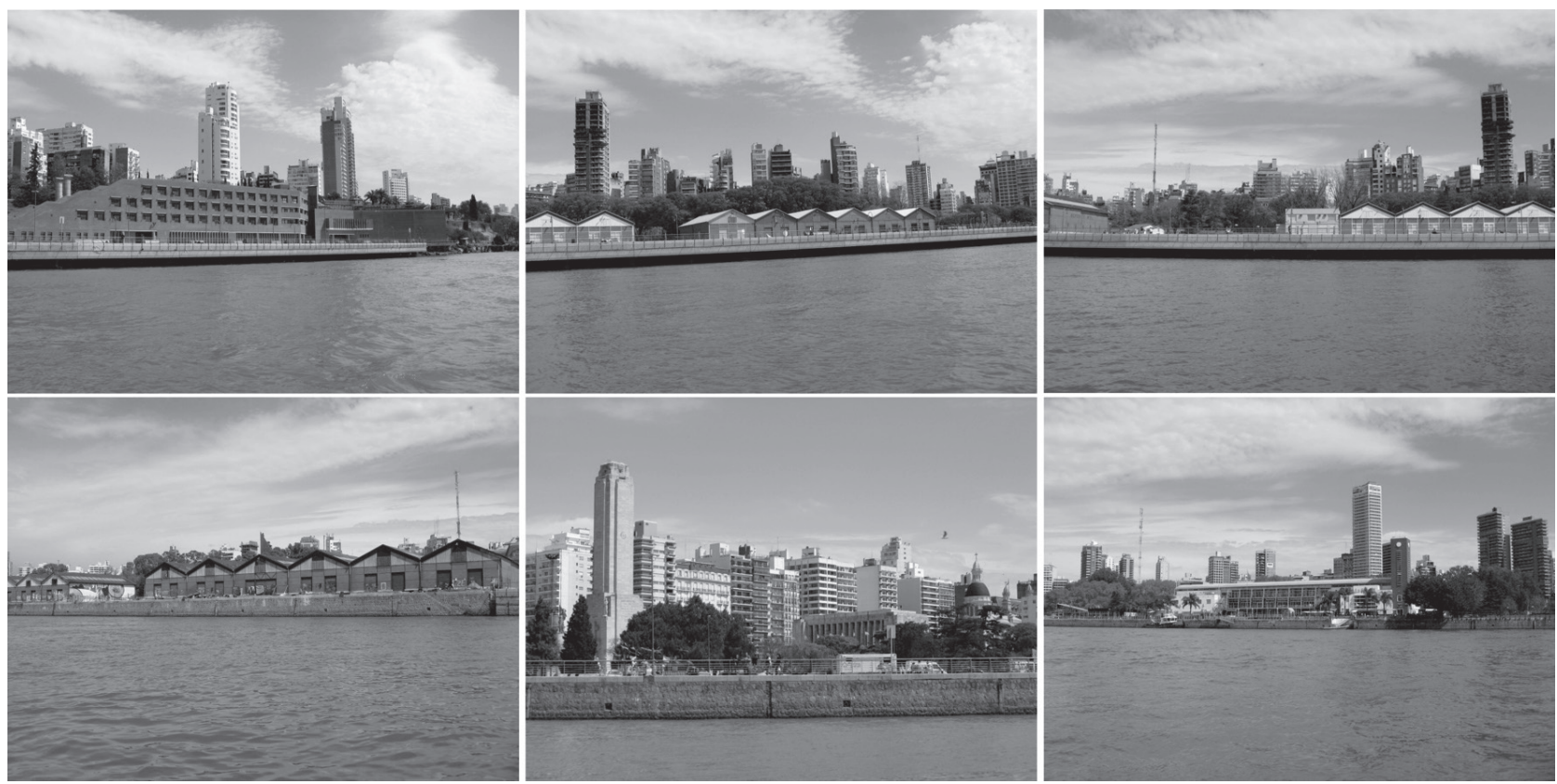

Figura 6. Reconversión costa central de Rosario (en curso) fotografiada desde el río Paraná

Fuente: fotografías de la autora

\section{Reconversión ribereña localidades de la región metropolitana de Rosario}

Gran parte de las localidades ribereñas estudiadas establecen una mayor relación recreativa con el río en las últimas décadas. Si bien presentan una marcada condición productiva, simultáneamente muestra enclaves vinculados con el ocio y el disfrute del río en varias de sus localidades. No obstante, la mixtura de usos diversos en cada municipio y en su relación con las localidades vecinas genera conflictos y demarca la carencia de políticas integradas.

En el frente ribereño metropolitano norte se encuentra la ciudad de Puerto General San Martín (PGSM), por ejemplo, que posee prácticamente la totalidad de su frente costero 


\section{LA REINVENCIŌN DEL RİO DESDE LO RECREATIVO \\ La transformación de la ribera Metropolitana de Rosario (Argentina) desde una mirada sobre el espacio público y las huellas patrimoniales}

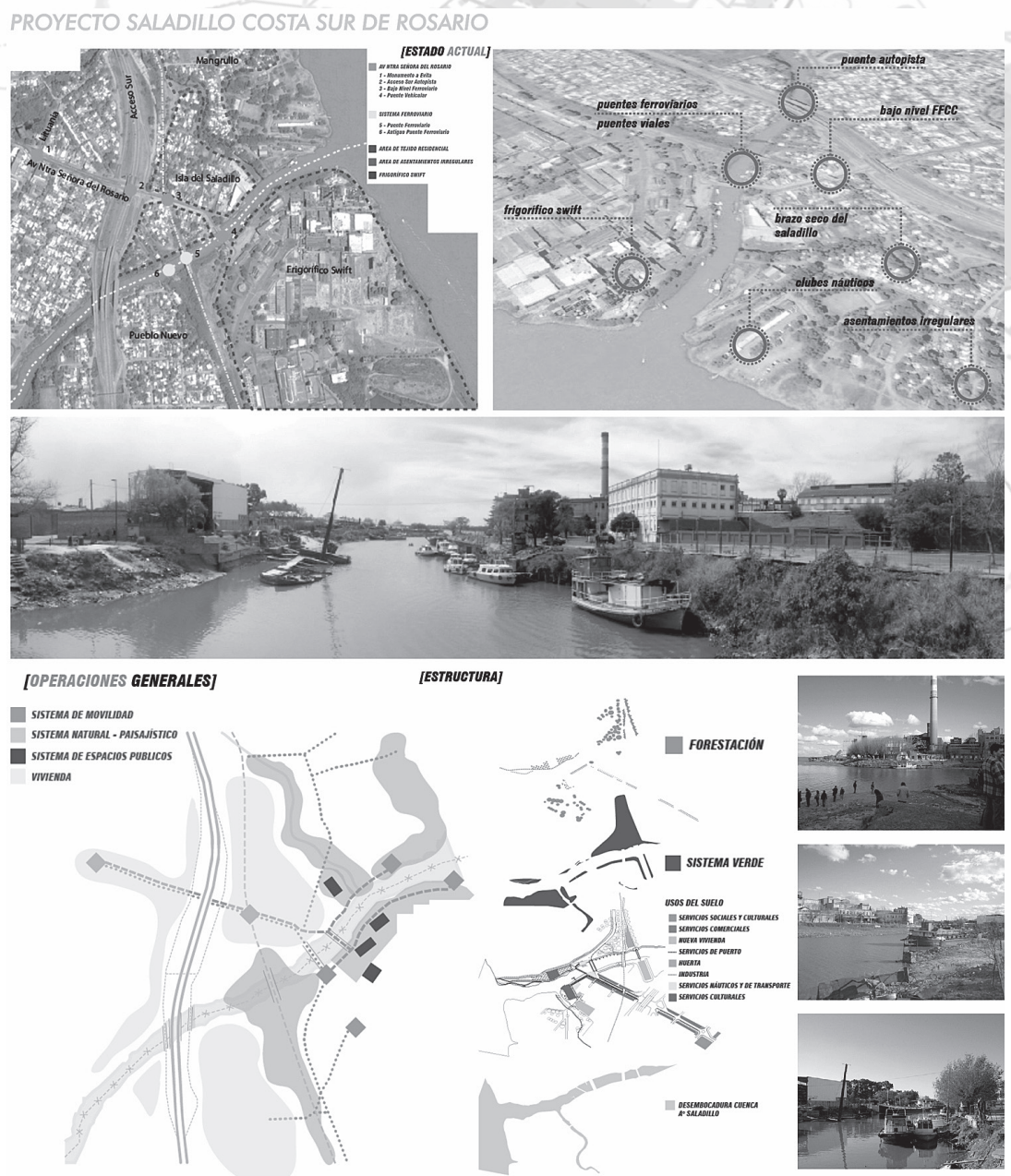




\section{Cecilia Inés Galimberti}

del río Paraná ocupado por usos productivos; mientras que destina como ámbito paisajístico-recreativo a la costa norte del arroyo San Lorenzo. Esta situación resulta opuesta a la que se plantea en el Municipio de San Lorenzo, en el cual se busca recuperar la ribera del Paraná para usos recreativos y condensar de actividades productivas al arroyo San Lorenzo (contrariamente a su localidad vecina). De manera que, mientras el borde norte de este arroyo es un ámbito de disfrute, su costa sur es productiva, y presenta un gran volcado de desechos industriales contaminantes. Ambos municipios se encuentran así imbricados en un conflicto de intereses opuestos. Esto sucede por la toma de decisiones localistas y la falta de políticas consensuadas y articuladas para este territorio, las cuales deben ser integradas y acordadas por todos los actores y jurisdicciones implicadas.

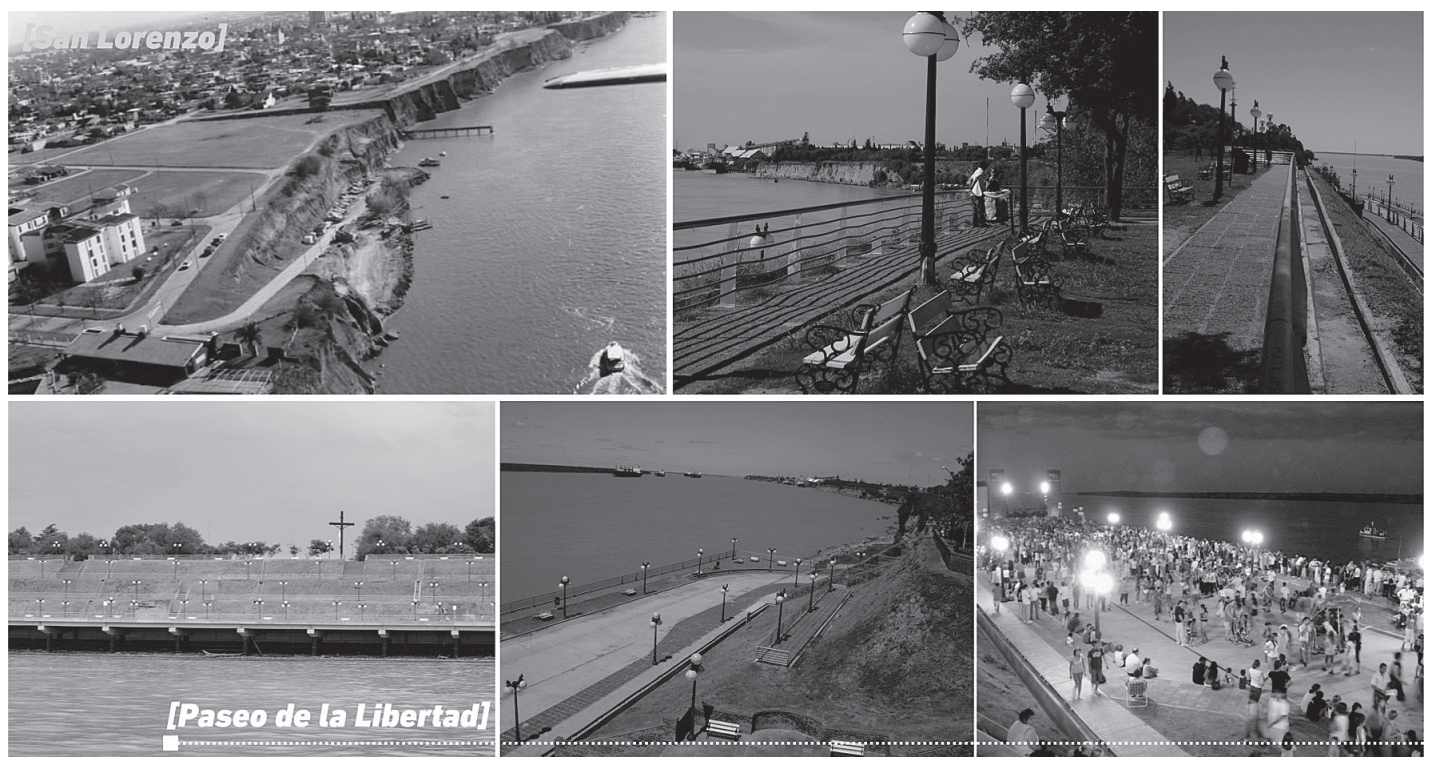

Figura 8. San Lorenzo. Transformación del frente ribereño del Paraná

Fuente: Municipalidad de San Lorenzo y fotografias de la autora 


\section{LA REINVENCIŌN DEL RĨO DESDE LO RECREATIVO \\ La transformación de la ribera Metropolitana de Rosario (Argentina) desde una mirada sobre el espacio público y las huellas patrimoniales}

Sin embargo, a pesar de esta situación productiva del Paraná en PGSM, también posee algunos enclaves recreativos. Entre los más significativos se encuentran: el lugar Histórico Nacional Batalla de Punta Quebracho, que además de su valor patrimonial, resulta un espacio público recuperado con mirador al río, y la Bajada del Morro, en la prolongación de calle Sarmiento, a través de la cual se accede a la barranca inferior de Bunge Muelle Pampa, con una pequeña playa natural. A su vez, se promueve desde el área de turismo de la localidad vivir el río a través de recorridos recreativos desde el puerto de cabotaje
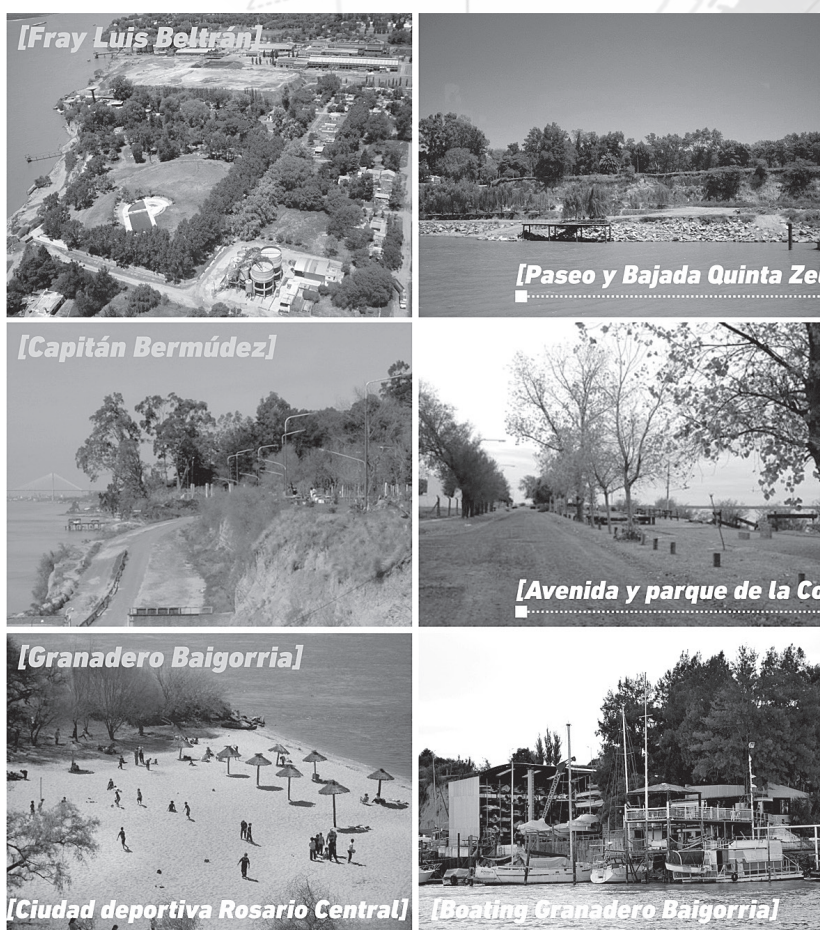
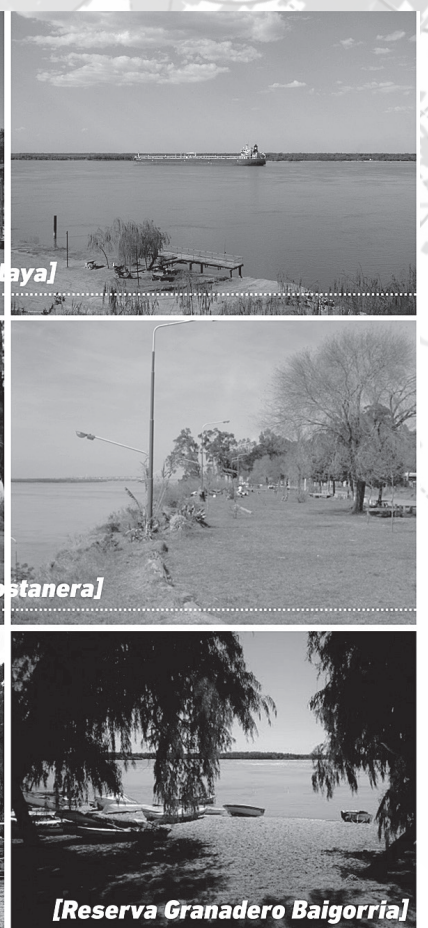

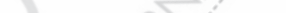

Figura 9. Frente costero de Fray Luis Beltrán, Capitán Bermúdez y Granadero Baigorria

Fuente: Municipalidad de Fray Luis Beltrán, Capitán Bermúdez y Granadero Baigorria; fotografias de la autora

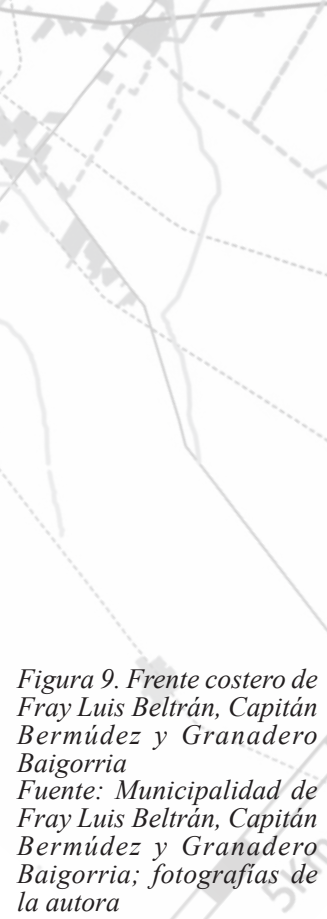

Cuaderno Urbano. Espacio, Cultura, Sociedad - Vol. 17 - N. 17 (Noviembre de 2014) - Pp. 145-172 - ISNN 1666-6186 


\section{Cecilia Inés Galimberti}

9- www.mpgsm.gov.ar/ciutur. php\#parque.

10- Se destacan: el predio del Seminario San Carlos Borromeo, el frente costero de la fábrica FAIART Argentina, el barrio de celulosa, de gran valor paisajístico y el bosque de celulosa. de PGSM, a fin de apreciar el paisaje productivo y recorrer las islas ubicadas frente a la localidad, "vivenciando las costumbres y vida del islero, asimismo conociendo la flora y la fauna", según promociona la página Web de la Municipalidad de PGSM.

La localidad de San Lorenzo, a pesar de resultar uno de los principales polos exportadores, también es una de las más importantes ciudades de este corredor, que establece, en los últimos años, una política de apertura de la ciudad hacia el río. Se plantea así recuperar para actividades recreativas su frente costero. Además del Polideportivo Municipal y del Club Náutico, con su respectiva guardería náutica, es de remarcar el recorrido superior ribereño de más de mil metros ininterrumpidos desde calle Tucumán hasta la bajada de calle San Luis. A su vez, el Paseo de la Libertad, inaugurado en 2009 y ubicado en la barranca a la altura del Campo de la Gloria, constituye uno de los principales ejemplos de espacio público costero de la ciudad, y resulta su principal mirador de la misma. Cultura, recreación y prácticas deportivas constituyen la tríada sobre la cual re-articular la trama urbana con el río y enfocar en este espacio el desarrollo turístico.

Fray Luis Beltrán también presenta la mayor parte de su frente costero destinado a actividades productivas. Sin embargo, se destacan el Camping Municipal y la Bajada Quinta Zelaya, en la cual recientemente se construyó el Paseo Quinta Zelaya, que incorporó diversos servicios recreativos de pesca y deportivos.

Asimismo, Capitán Bermúdez recupera parte de su frente costero a través de la avenida Costanera y el Parque de la Costanera; se destacan la bajada Sarmiento - conocida como bajada de los pescadores - y la denominada bajada de las lanchas, al final de la cual se encuentran el Club Náutico Bermúdez, y la isla Los mástiles, ubicada frente a esta localidad. No obstante, aún se encuentran grandes espacios ribereños ${ }^{10}$ - si bien de propiedad privada-, que constituyen áreas de oportunidad para una reconversión continua e integral de la ribera local.

La ciudad de Granadero Baigorria presenta diversos enclaves de vinculación con el río. Se destacan la avenida Costanera - si bien no es continua en toda la ciudad, presenta en su totalidad una gran extensión-, las distintas bajadas de la ciudad a la costa - especialmente la bajada El Espinillo y la bajada Estrada-, la Reserva Baigorria, la Ciudad Deportiva del Club Rosario Central y caletas de embarcaciones como Boating Granadero Baigorria - Norte y Sur - y el Tifón WaterPlanet (en construcción). Asimismo, este frente costero se encuentra fragmentado por diversos usos (residenciales, productivos, recreativos y de asentamientos irregulares en la barranca). 


\section{LA REINVENCIÓN DEL RÍO DESDE LO RECREATIVO}

La transformación de la ribera Metropolitana de Rosario (Argentina) desde una mirada sobre el espacio público y las huellas patrimoniales

A su vez, en la ribera occidental sur, al no conformarse un continuo urbano, se presentan numerosos sectores de oportunidad para nuevos desarrollos paisajísticos y públicosrecreativos. No obstante, diversas localidades de esta ribera presentan problemáticas por la superposición de usos conflictivos. Por ejemplo, la ciudad de Villa Gobernador Gálvez no presenta espacios ribereños integrados a la planta urbana, si bien existen espacios de costa libres - con la presencia de asentamientos irregulares, principalmente de pescadores-, estos no han sido intervenidos ni desarrollados desde una política de recuperación y de articulación con el ejido. Resultan así espacios expectantes de transformación, que dada la gran ocupación de la ribera de esta localidad en usos productivos - especialmente frigoríficos-, sería de un gran valor para la ciudad recuperarlos con fines paisajísticos, recreativos y deportivos para toda la comunidad.

Una situación similar presenta Alvear, cuyo frente costero se encuentra completamente destinado a usos productivos y portuarios (Cargill y Ultrapetrol); solo se encuentra un fragmento de ribera baja de gran valor paisajístico, pero que está usurpado por asentamientos irregulares de pescadores. Además, esta localidad limita al sur con el arroyo Frías; sin embargo, al encontrarse sobre el mismo el Parque Industrial de Alvear - junto a otros componentes productivos-, este arroyo se encuentra degradado y con altos valores de contaminación. Por este motivo, esta localidad se encuentra en conflicto con Pueblo Esther, poblado que limita al sur del arroyo Frías. De manera que se reitera la situación antes explicada para el arroyo San Lorenzo entre ambas jurisdicciones vecinas: mientras una localidad utiliza el arroyo para usos industriales — presentando volcado de desechos-, la otra lo utiliza con fines paisajísticos-recreativos. Nuevamente se destaca la carencia de políticas integrales territoriales a nivel regional.

En la comuna de Pueblo Esther, a diferencia de estas dos últimas localidades - Villa Gobernador Gálvez y Alvear - , predomina en su ribera usos recreativos y residenciales — si bien se presentan diversas areneras-. El mayor conflicto que existe es la ocupación de lotes privados hasta el río, ya que no se respeta el camino de Sirga (estipulado por el Código Civil $^{11}$ ). Sin embargo, a su vez, se presentan diversos enclaves de uso público, como la bajada junto al arroyo Frías, el sector de costa baja justo a su desembocadura - a pesar de existir asentamientos de pescadores-, el Parque Vernazza, el Camping Municipal Pueblo Esther y el Paseo Ribereño.

11- El Art. 2639 dél Código Civil plantea: "Los propietarios limitrofes con los ríos o con canales que sirven a la comunicación por agua, están obligados a dejar una calle o camino público de 35 metros hasta la orilla del río, o del canal, sin ninguna indemnización. Los propietarios ribereños no pueden hacer en ese espacio ninguna construcción, ni reparar las antiguas que existan, ni deteriorar el terreno en manera alguna". 


\section{Cecilia Inés Galimberti}

La ribera de General Lagos presenta diversos espacios de oportunidad, especialmente la ribera baja y la isla que se encuentra en esta localidad. Es necesario establecer políticas de usos de suelo y lineamientos de ordenación territorial, antes de que continúe siendo ocupada por barrios cerrados y componentes productivos, como comenzó a suceder en los últimos años.

El frente costero de Arroyo Seco se encuentra fragmentado por usos productivos, residenciales y recreativos - principalmente clubes privados - ; tampoco presenta políticas de ordenación o lineamientos articulados de su ribera. Una situación similar se presenta con Fighiera, en la cual se destaca especialmente el arroyo Pavón, de gran valor paisajístico. Además comprende parte de la isla del Sol, junto a Villa Constitución — ciudad que presenta su mayor jurisdicción-. Resulta una reserva ecológica protegida de importante valor ambiental y turístico, que es necesario potenciar y proteger.

Figura 10. Ciudad de Victoria y sus

$$
\begin{array}{r}
\text { islas } \\
\text { Fuente: } \\
\text { Municipalidad } \\
\text { de Victoria y }
\end{array}
$$

fotografias de la

autora
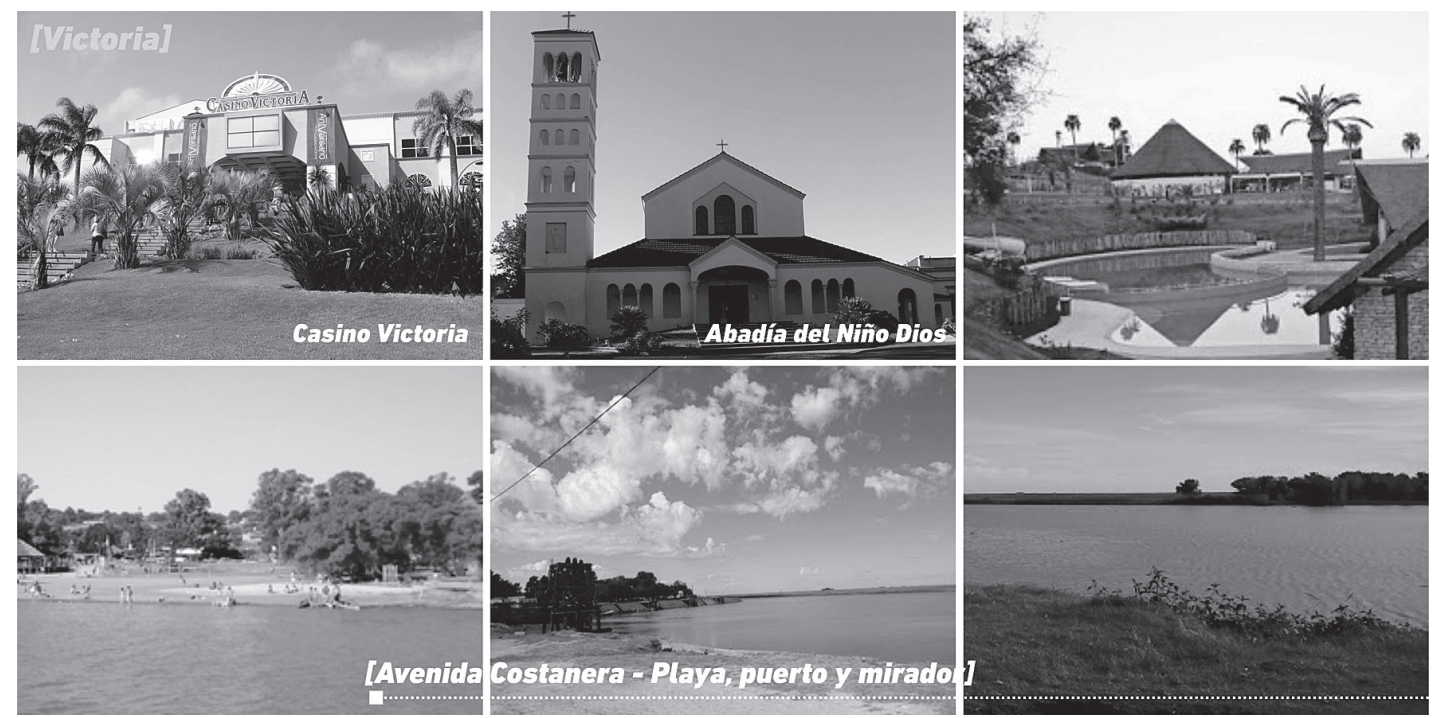


\section{LA REINVENCIÓN DEL RÍO DESDE LO RECREATIVO \\ La transformación de la ribera Metropolitana de Rosario (Argentina) desde una mirada sobre el espacio público y las huellas patrimoniales}

Por otro lado, especialmente en la última década, la ciudad de Victoria — ubicada en la orilla oriental del Paraná - incrementa su rol abocada principalmente a lo recreativo y lo turístico. Las actividades vinculadas con el río y sus islas, los balnearios, muelles de pesca, puertos deportivos, la avenida costanera, junto a la inauguración del Casino de Victoria, la presencia de la abadía benedictina del Niño Dios y la inauguración reciente del complejo
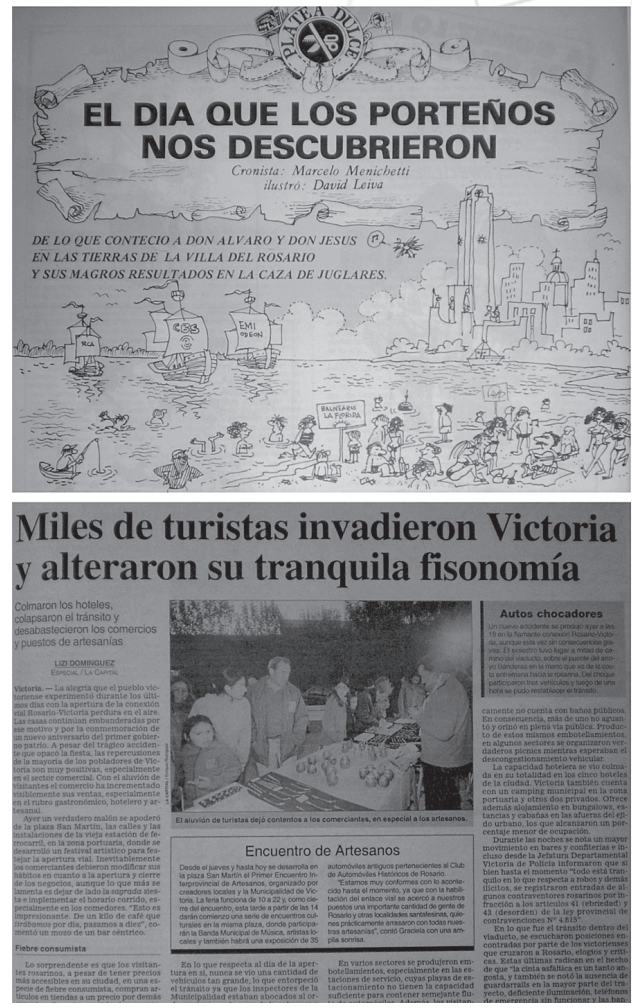
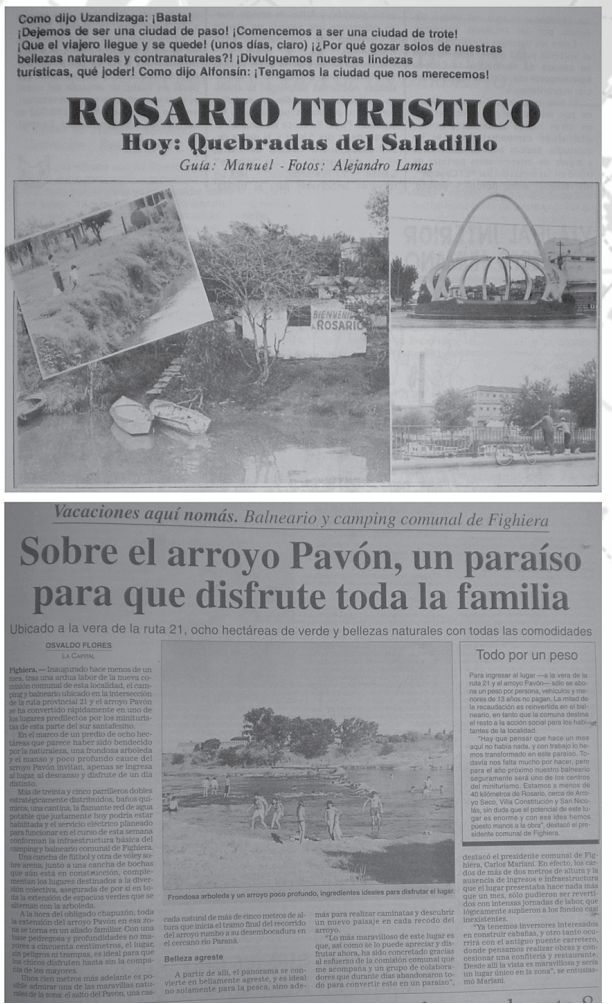

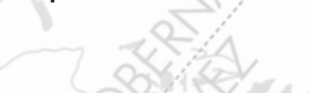

Figura 11. Turismo en Rosario y su región

Fuente: arriba, Revista Risario $N .^{\circ} 20$ Año 1985; abajo izquierda, Diario La Capital del 25 de mayo de 2003. Abajo derecha: Diario La Capital del 13 de enero de 2002 


\section{Cecilia Inés Galimberti}

12- Según palabras del intendente Natale en la creación de la Comisión Asesora de Turismo en febrero de 1982.

$\overline{13-U_{G A R T E}, \text { E. L. (1984) }}$ "Rosario: más miniturismo", en Diario La Capital, 4 de julio de 1984. termal "Victoria del Agua", entre otros componentes recreativos, posicionan a Victoria cono nodo turístico regional. Sobre este tema vamos a profundizar a continuación.

\section{NUEVO ROL DEL TURISMO REGIONAL}

Durante estas últimas tres décadas cambia completamente el posicionamiento turístico de Rosario y la región. El rol paisajístico-recreativo que adquiere el río y sus islas posiciona al sector de estudio en un nodo turístico de gran atractivo. No obstante, este posicionamiento se construye de forma gradual en el tiempo, comenzando con aspiraciones bajas - y prácticamente limitado a la ciudad de Rosario - hasta resultar un polo turístico a nivel nacional, e incorporando varias localidades de la región - especialmente Victoria y sus islas-. Por ejemplo, en el año 1983, se constituye la Comisión Asesora Municipal de Turismo con el fin de promover la actividad en Rosario, pero desde las bases de dicha comisión se considera que Rosario no posee "atributos naturales de excepción", sino que tiene "aspiraciones modestas" 12 , ya que ofrece aspectos destacables aunque desconocidos fuera del ámbito local. De manera que entre los años 1984-1985, se presentan propuestas de diversos frentes para promover turísticamente a esta ciudad.

En primer lugar, se enfoca la mirada en que los propios rosarinos y los habitantes del Gran Rosario no conocen intrínsecamente a la ciudad, sosteniendo que en los años previos al retorno democrático "todos la han olvidado a tal punto que Rosario fue adquiriendo la condición de cenicienta, que aún no fue descubierta en sus posibilidades que consideramos pueden satisfacer a todos los gustos. [...] Es hora de despertar a Rosario de su condición de cenicienta para proyectarla en una primera instancia como centro de miniturismo [...] Es una convocatoria a los entes oficiales para que Rosario deje de ser la cenicienta, la ciudad no visitada, la que ¿para qué ir hasta allá?, si no tiene nada para $v e^{\prime \prime 13}$ (Diario La Capital, 4 de julio de 1984).

Se considera que es necesario comenzar fomentando el miniturismo, porque una vez financiado este, el turismo nacional e internacional llegará como consecuencia. Se promueve así esta postura desde diversos frentes - Concejo Deliberante, Municipalidad, actores vinculados con la historia local, entre otros-. Por ejemplo, en 1984 se presenta al Concejo un proyecto para promocionar turísticamente a la ciudad de Rosario, vinculando esta nueva mirada de difusión turística con la nueva condición democrática. 


\section{LA REINVENCIŌN DEL RÍO DESDE LO RECREATIVO \\ La transformación de la ribera Metropolitana de Rosario (Argentina) desde una mirada sobre el espacio público y las huellas patrimoniales}

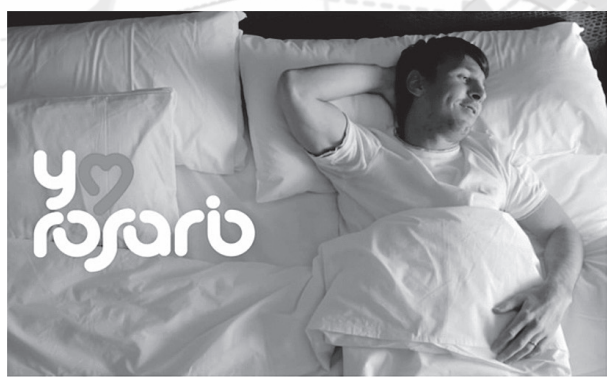

CONOCÉ
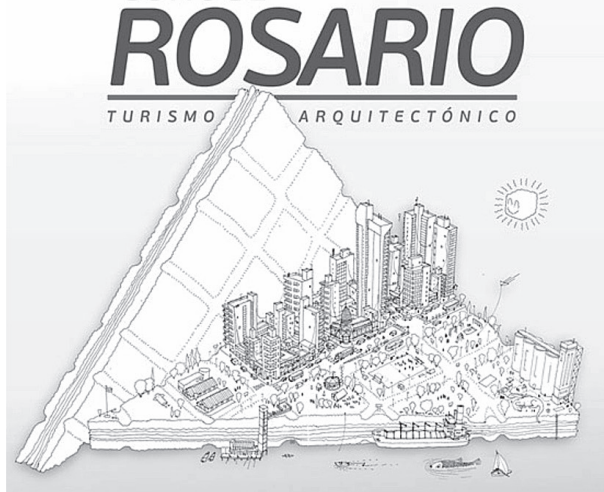
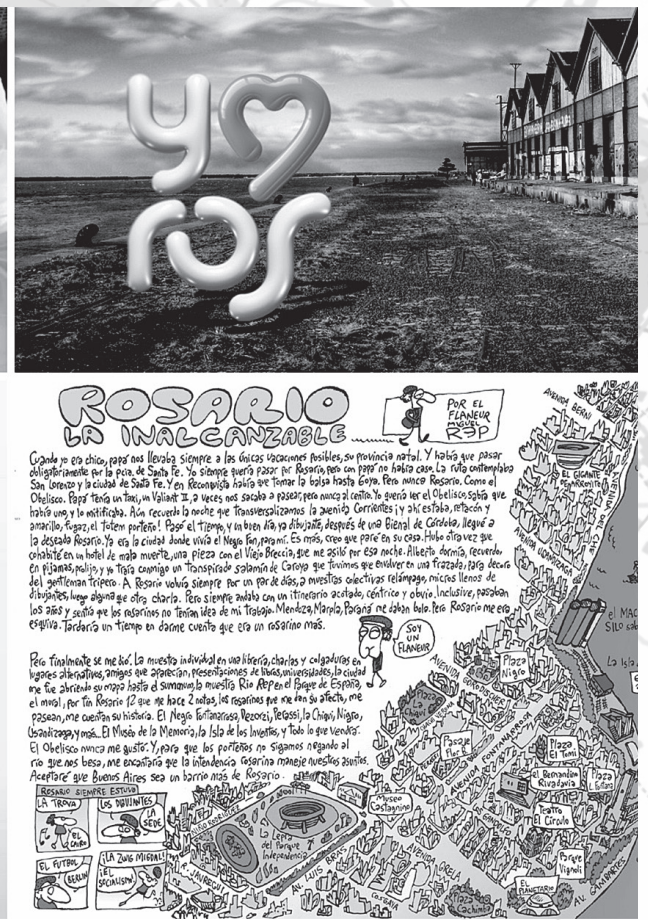

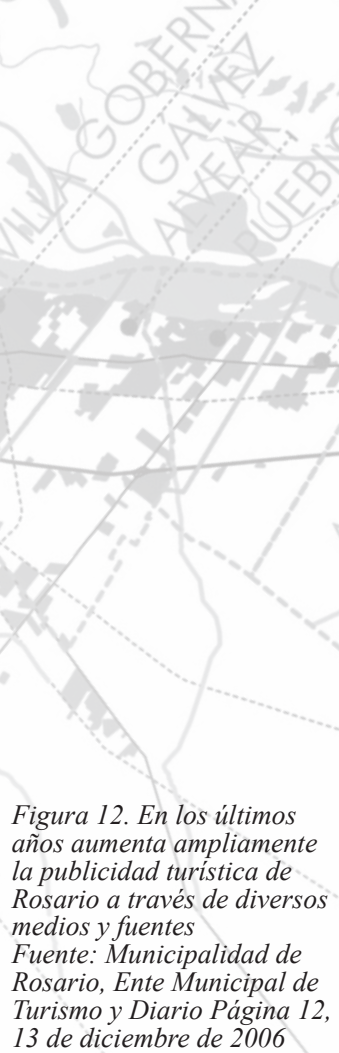

La postura de difundir el turismo también es tomada por el gobierno provincial, que realiza diversas tareas de divulgación y promoción de Santa Fe Turística. También así se parte de la iniciativa de promover el llamado "mini-turismo" convocando y atrayendo en primer lugar a los propios santafesinos.

Los balnearios y los espacios vinculados con el río y los arroyos son los enclaves principales elegidos para la promoción turística provincial. Es así que, en los últimos años de 


\section{Cecilia Inés Galimberti}

14- Como plantean un grupo de empresarios turísticos en las reuniones con el Poder Ejecutivo local en 1988.

15-La propuesta dada por el área de turismo del municipio propone "jornadas de pesca con guía de pesca con cañas para pescar, anzuelos, carnada; almuerzo de pescado, desayuno y cena. Noche en carpa, con todo incluido". la década del 80 , se incrementan notablemente las publicidades en diversos medios de comunicación de las opciones turísticas que presentan Rosario y su región. Es notable cómo en estas propuestas ocupan el lugar central los espacios ribereños, tanto los parques y plazas ubicados en el tramo costero, los clubes y balnearios, como del paseo ribereño - recientemente inaugurado en esos años-, que permite la continuidad del recorrido paisajístico. Con eslóganes recurrentes, como Ruta del sol... belleza y encanto del río Paraná, se publicitan reiteradamente los clubes ribereños, las guarderías náuticas, incrementando así, año a año, en gran medida los ciudadanos que adoptan estas opciones.

El desarrollo turístico regional se fortalece en los años siguientes, a fin de instaurar la "mentalidad turística" ${ }^{14}$ entre los rosarinos y desarrollar la infraestructura necesaria para llevar a cabo las nuevas propuestas y el incremento de visitantes. De manera que en las dos últimas décadas se logra posicionar a Rosario como un foco de importancia de turismo a nivel nacional. A su vez, eventos de importancia a nivel internacional, que toman lugar en la ciudad, como el III Congreso de la Lengua, el Mundial de Hockey o el Rally Dakar de 2014, entre otros, fueron claves en el posicionamiento de Rosario y su región en materia de atracción de visitantes. De este modo, desde varios años, Rosario se encuentra frecuentemente con su plaza hotelera ocupada al ciento por ciento, y con sus espacios ribereños colmados de visitantes.

Pero no solo Rosario potencia su rol turístico en estos años, sino gran parte de las localidades ribereñas promocionan sus opciones y propuestas. Justamente, es nuevamente el río y sus islas el foco que presenta mayores atractivos, aun en localidades que exhiben su frente ribereño mayormente ocupado por usos productivos. Localidades como Puerto General San Martín enfocan su promoción turística "nacional e internacional" — como ellos mismos indican - en las posibilidades de vivir el río, desde paseos recreativos y culturales en lancha, hasta alternativas de turismo de pesca all inclusive. ${ }^{15}$ Frente a la congestión náutica que sucede principalmente los fines de semana de verano en Rosario y las islas frentistas a dicha ciudad, varias localidades ribereñas de la región proponen un turismo alternativo, con mayor vivencia de la naturaleza, en un paisaje aún poco explotado.

De este modo, las orillas del Paraná y sus islas se constituyen, en conjunto, como un polo de atractivo turístico regional, más allá de las jurisdicciones de cada localidad o provinciales (Santa Fe y Entre Ríos). Se suceden así diversas rutas turísticas-culturales posibles: 


\section{LA REINVENCIÓN DEL RÍO DESDE LO RECREATIVO}

La transformación de la ribera Metropolitana de Rosario (Argentina) desde una mirada sobre el espacio público y las huellas patrimoniales

desde el turismo religioso, constituyéndose como polos centrales del mismo el convento Franciscano San Carlos en San Lorenzo y la abadía benedictina del Niño Dios en Victoria, conectando numerosas iglesias y oratorios de diferentes fechas fundacionales en este territorio; el turismo ambiental o ecoturismo, caracterizado por conocer las áreas naturales protegidas, especialmente los diversos enclaves naturales de valor ambiental como barrancas e islas en este delta del Paraná, a partir de la mirada atenta sobre este territorio que contribuya a su conservación; el turismo de pesca, el cual revaloriza la actividad de diversas poblaciones asentadas en estas barrancas como a clubes y cooperativas de pesca; el turismo productivo, que permite el recorrido fluvial de estos grandes componentes portuarios e industriales característicos de la ribera occidental del Paraná; el turismo cultural, que conecta los distintos acontecimientos históricos y patrimoniales de esta región, desde el conocimiento de los habitantes nativos, como de la historia escrita desde los primeros inmigrantes de este territorio. Estas rutas turísticas aquí propuestas simplemente son expuestas a modo de ejemplo, a fin de demostrar la enorme potencialidad turística de este ámbito geográfico, si se amplía la escala de la mirada y se piensa en conjunto, de manera integrada.

\section{ALGUNAS REFLEXIONES FINALES}

A nivel mundial, los espacios ribereños históricamente destinados a actividades portuarias e industriales, frente a su obsolescencia o al cambio en los modos de producción, se posicionan como espacios de oportunidad. Es así que se posibilita establecer nuevos diálogos entre los componentes fluviales y la trama urbana, a partir de otros usos y nuevas apropiaciones de estos espacios.

La reinvención del río desde lo recreativo significa en Rosario y su región la concreción de viejos anhelos de la población del disfrute de la ribera y las islas para el desarrollo de diversas actividades vinculadas con el ocio. No obstante, es a partir de la década del 80 , con el retorno democrático, cuando comienza la transformación del frente costero central de la ciudad de Rosario para espacio público y actividades culturales y recreativas. Con el transcurrir de los años, este fragmento urbano resulta el espacio elegido para representar a Rosario frente a los otros. Es el tramo de principal atracción turística de la ciudad, la principal imagen de marketing urbana. 


\section{Cecilia Inés Galimberti}

No obstante, a pesar del valor que presenta esta reconversión ribereña, resulta necesario reflexionar sobre el rol efectivo de la transformación de este sector en el conjunto del sistema del frente costero, no solo urbano, sino a nivel metropolitano: ¿qué sectores de la población se apropian cotidianamente de este sector?; ¿cómo se vincula este espacio estratégico central en relación con los de la periferia urbana?; ¿resulta un espacio público inclusivo de encuentro de todas las clases?; ¿qué políticas complementarias es necesario implementar para lograr una mayor equidad en el uso recreativo de estos espacios?

Asimismo, al analizar las iniciativas posteriores de transformación ribereña de otras localidades de la Región Metropolitana de Rosario, vemos que muchas veces se realizan de forma fragmentada, a nivel local, dejando de lado la perspectiva regional y la mirada de la ribera como un corredor cultural continuo. De este modo, resulta necesario establecer políticas integradas para toda la Región Metropolitana de Rosario, a través de una mirada atenta al ambiente y al territorio, ya que cada localidad presenta mayores potencialidades al formar parte de una red mucho más rica y fortalecida.

Por ello, es necesaria una mirada crítica continua sobre las intervenciones y desarrollos de transformación territorial, a fin de que esta recuperación ribereña metropolitana no se convierta en un mero producto del mercado y del consumo. Lo recreativo como objeto del mercado tiende a anular las lógicas propias del territorio, poniéndolo en riesgo de degradación y de desterritorialización. Que el afán de incrementar el turismo no elimine los valores de identidad local — que paradójicamente, son los que en primer lugar atraen a nuevos visitantes - ; de lo contrario, la reinvención del río desde el punto de vista recreativo debe representar una oportunidad para producir nuevas territorialidades, entendidas como creación de calidad ambiental y calidad de vida, como valoración de la identidad urbana-territorial, de sentido de pertenencia en los valores propios (MAGNAGHI, 2011).

Si bien las prácticas vinculadas con el río y sus islas se encuentran en profunda transformación, resultan una oportunidad para repensar la direccionalidad de estos procesos y reflexionar sobre la sostenibilidad de nuestro territorio. En este sentido, es necesario que, en la vorágine de reconquistar el río, no seamos colonos que destruyan sus lazos y nieguen sus lógicas intrínsecas, sino que descubramos en él un modo de vida más atento a su identidad fluvial. 


\section{LA REINVENCIÓN DEL RÍO DESDE LO RECREATIVO}

La transformación de la ribera Metropolitana de Rosario (Argentina) desde una mirada sobre el espacio público y las huellas patrimoniales

\section{BIBLIOGRAFÍA}

BRIGUET, Daniel (1988) El encapuchado no se rinde. El resorte libros, Rosario.

FERRER, Ángel; FERNANDEZ PRIOTTI, Carlos (2001) Ferrocarriles en Rosario.

Asociación Rosarina Amigos del Riel, Rosario.

GALIMBERTI, Cecilia (2012). "El rol de la democracia en la planificación urbana. Caso ciudad de Rosario, Argentina (1983-1993)”. En: Revista Proyección N. ${ }^{\circ} 12$, Vol VI, Junio de 2012.

MAGNAGHI, Alberto (2011) El proyecto local. Hacia una conciencia del lugar. Architectonics-UPC, Barcelona.

MATEOS, Alicia (2007) Plan de Ordenamiento Territorial Costa Metropolitana del Gran Rosario. Cordón Sur. Diagnóstico. Consejo Federal de Inversiones, Oficina de Asuntos Metropolitanos, Provincia de Santa Fe.

MATEOS, Alicia, DOCOLA, Silvia, PUIG, Mónica (2007) Patrimonio: Del Saladillo al del Medio - Cordón Sur - Costa Area Metropolitana Gran Rosario. Consejo Federal de Inversiones, provincia de Santa Fe.

MARTÍNEZ DE SAN VICENTE, Isabel (1997). "La sutil belleza de la ciudad aluvional". En: Summa + 33, Buenos Aires.

RIGOTTI, Ana María (2007) Plan de ordenamiento territorial. Costa metropolitana del Gran Rosario. Cordón norte, Informe Final. Consejo Federal de Inversiones, Oficina de Asuntos Metropolitanos, provincia de Santa Fe.

RIGOTTI, Ana María, HEREDIA, Lina (2007) Inventario Patrimonio Natural y Construido. Cordón Norte - Costa Área Metropolitana Gran Rosario. Consejo Federal de Inversiones, provincia de Santa Fe.

MUNICIPALIDAD DE ROSARIO (1986). "Informe preliminar. Plan Director de Rosario". Secretaría de Planeamiento, Rosario.

MUNICIPALIDAD DE ROSARIO (1991). “Actualización del Plan Regulador y Bases Documentales para la revisión del Código Urbano". Secretaría de Planeamiento, Rosario. MUNICIPALIDAD DE ROSARIO (1998). "Plan Estratégico Rosario 1998 - PER". Rosario. 


\section{Cecilia Inés Galimberti}

\section{Fuentes documentales}

Archivo Museo de la ciudad de Rosario.

Archivo Municipalidad de Rosario, Secretaría de Planeamiento.

Archivo Revista Risario.

Archivo Diario la Capital.

Archivo Diario Página 12. 